\title{
A clinical audit of thalassaemia management at the Lady Ridgeway Hospital for Children, Colombo
}

\author{
P S Samarakoon ${ }^{1}$, A P Wijesuriya ${ }^{2}$ \\ Sri Lanka Journal of Child Health, 2011; 40: 48-53
}

(Key words: clinical audit; thalassaemia; blood transfusion; chelation; desferrioxamine; deferiprone; iron overload)

\begin{abstract}
Objective: To assess the adherence of management of beta thalassaemia major patients at Lady Ridgeway Hospital to an established standard treatment protocol

Method: A clinical audit was carried out in all six medical wards of Lady Ridgeway Hospital from $1^{\text {st }}$ February 2008 to $31^{\text {st }}$ March 2008 with retrospective data collected over the period $1^{\text {st }}$ January 2005 to $31^{\text {st }}$ December 2007. The study population comprised all beta thalassaemia major patients admitted to the wards during the study period. Patients who did not give consent and those having other transfusion dependant anaemias were excluded from the study. The study instrument used was a pretested structured data collection form. Data collection was done by referring the past medical records. Data on 'compliance' was based on recall by the parent. Data analysis was done on a Microsoft Excel worksheet.
\end{abstract}

Results: During the study period data was collected from 61 patients. Age at time of diagnosis ranged from 2 months to 5 years. All patients had their diagnosis confirmed by haemoglobin electrophoresis, high performance liquid chromatography or both tests. Pre-transfusion haemoglobin levels ranged from $4.1 \mathrm{mg} / \mathrm{dl}$ to $11.2 \mathrm{mg} / \mathrm{dl}$. Number of blood transfusions per year ranged from 4-18 per year. Almost $50 \%$ of the patients had serum ferritin levels above the potentially cardiotoxic level of $2500 \mu \mathrm{g} / \mathrm{l}$.

Conclusions: Compliance of the patients with the treatment protocol was unsatisfactory. A high proportion of patients had cardiotoxic levels of serum ferritin.

${ }^{1}$ Senior Registrar, ${ }^{2}$ Consultant Paediatrician, Lady Ridgeway Hospital, Colombo

(Received on 23 June 2010: Accepted on 27 August 2010)

\section{Introduction}

In Sri Lanka there are 2000 estimated thalassaemia patients ${ }^{1}$, mainly scattered in Wayamba, Uva and North Central provinces. Out of this, beta thalassaemia major is predominant with an estimated annual homozygous birth rate of about hundred ${ }^{2}$. Improvement in quality of care during the last decade has contributed to an increased number of survivors in the country. These patients are mainly managed by government hospitals that possess blood transfusion facilities. The main thalassaemia centre in Kurunegala is supported and guided by a team of international experts under the supervision of the Ministry of Health.

Standard treatment in developed countries comprises regular blood transfusions, maintaining haemoglobin at an 'acceptable' level and introduction of chelation therapy (mainly using subcutaneous desferrioxamine infusions) when there is evidence of iron overload. Newer oral chelating agent deferasirox has recently been introduced in these countries. In Sri Lanka desferrioxamine is used commonly while use of oral deferiprone (L1) though less expensive has not been popular due to fear of side effects ${ }^{3,4,5}$. Sri Lanka still has no comprehensive thalassaemia control programme.

Management of thalassaemia patients in Sri Lanka is a major health care burden due to the high financial cost of treatment. Cost of care for thalassaemia is 5\% of the national health care budget ${ }^{1}$. The World Health Organisation has estimated that an annual average consumption of 27 units of blood and Sri Lankan Rupees 400,000 worth of the drug are needed to manage each patient according to recommended standards ${ }^{2}$. However, despite high expenditure, high morbidity and limited life expectancy of thalassaemia patients in Sri Lanka are a cocern ${ }^{6}$.

The Sri Lanka College of Paediatricians has initiated formulation of national guidelines for management of thalassaemia so as to provide quality treatment for all 
the patients in the country. Yet, a full document is still not available for uniform management in Sri Lanka. Guidelines published by the Thalassaemia International Federation are commonly used in Sri Lanka to manage thalassaemia patients and are used as an audit tool in this study.

Thalassaemia, being a chronic disease needs optimum treatment in order to achieve a reasonable longevity extending over 40 years $^{7,8,9}$. This costly treatment includes regular blood transfusions and almost daily infusions for chelation therapy. Analysis of the status of care given in Sri Lanka will be useful in formulating national guidelines to facilitate better care for the thalassaemia patients in Sri Lanka.

\section{Objectives}

\section{General objective}

To assess the adherence of management of beta thalassaemia major patients at Lady Ridgeway Hospital to an established standard treatment protocol

\section{Specific objectives}

- To assess demographic details of the study population

- To analyse investigation methods used to confirm diagnosis

- To assess completeness of family screening

- To assess maintenance of medical records

- To determine adherence to hepatitis B immunization protocol

- To determine adherence to protocol regarding appropriate age for splenectomy

- To describe regular blood transfusions with regard to frequency and volume per year

- To determine whether blood transfusions had been carried out when pre-transfusion haemoglobin was at the appropriate levels

- To identify if serum ferritin levels have been done according to protocol

- To describe the serum ferritin levels in the study population

- To describe popularity of desferrioxamine and deferiprone as chelating agents

- To determine if desferrioxamine and deferiprone had been used by the patients according to protocol

- To determine compliance to prescribed chelating agents

- To describe the complications of disease and treatment

\section{Method}

A clinical audit was carried out in all six medical wards of Lady Ridgeway Hospital (LRH) from $1^{\text {st }}$ February 2008 to $31^{\text {st }}$ March 2008. Retrospective data collection was from $1^{\text {st }}$ January 2005 to $31^{\text {st }}$ December 2007. The study population comprised all beta thalassaemia major patients admitted to the wards during the study period. Patients who did not give consent and those having other transfusion dependent anaemias were excluded from the study. The study instrument used was a pretested structured data collection form. Cases were defined as beta thalassaemia patients diagnosed by haemoglobin electrophoresis, high performance liquid chromatography (HPLC) or genetic analysis.

Thalassaemia patients were identified by checking the ward admission registers daily during the study period. They were included in study after checking the investigations done to confirm the diagnosis. Data collection was done by referring the past medical records. All patients have 'thalassaemia record books' which they bring when admitted to the wards. New information is recorded in these books before discharge. Most information was obtained from the record books. In addition, some wards maintain separate 'ward record books' for individual patients in the ward. When adequate information could not be obtained from these sources relevant bed head tickets were traced from the hospital record room. Data on 'compliance' was based on recall by the parent after explaining the need for accurate information. Principal investigator interviewed the parents and collected data. Data analysis was done on a Microsoft Excel worksheet. Ethical clearance for the study was obtained from the Ethics Review Committee, Faculty of Medicine, University of Colombo.

\section{Results}

During the study period data was collected from 61 patients of whom 32 were males. Ages ranged from 4 months to 24 years. Forty patients had their diagnosis confirmed by haemoglobin electrophoresis, 14 by HPLC and 7 using both tests. Age at the time of diagnosis ranged from 2 months to 5 years (Table 1).

Table 1

Age at time of confirmation of diagnosis

\begin{tabular}{|l|c|}
\hline \multicolumn{1}{|c|}{ Age } & Number diagnosed \\
\hline$<3$ months & 03 \\
\hline $3-6$ months & 30 \\
\hline $7-11$ months & 21 \\
\hline $1-5$ years & 07 \\
\hline
\end{tabular}


Child health development records of the 3 children less than 3 months of age indicated severe acute undernutrition with the weight for age $<3^{\text {rd }}$ centile. In the 7 children diagnosed after 1 year of age confirmation of diagnosis was delayed in 5 due to previous blood transfusions and in 2 due to inconclusive reports.

Screening of parents and siblings for carrier or disease status is usually done by performing mean cell volume (MCV), haemoglobin electrophoresis or HPLC. Out of the 61 patients, parents were not screened for carrier status in 4 and siblings were not screened in 19 (data was not available in 14 to determine screening status).

All patients were having past medical records (thalassaemia record books), but in 17, all needed information could not be traced. In 5, hepatitis B immunization was not age appropriately completed.

Pre-transfusion haemoglobin levels (Table 2) ranged from 4.1 to $11.2 \mathrm{mg} / \mathrm{dl}$. Most values were between 7 $-8 \mathrm{mg} / \mathrm{dl}(2007=64 \%, 2006=68.5 \%, 2005=67.3 \%)$. Most importantly none had a consistent pretransfusion haemoglobin level between 9-10.5 g/dl.

Table 2

Pre-transfusion haemoglobin levels

\begin{tabular}{|c|c|c|c|}
\hline Year & $\begin{array}{c}>9 \text { g/dl } \\
\text { No. (\%) }\end{array}$ & $\begin{array}{c}\mathbf{9 - 6} \text { g/dl } \\
\text { No. (\%) }\end{array}$ & $\begin{array}{c}<6 \text { g/dl } \\
\text { No. (\%) }\end{array}$ \\
\hline 2007 & $43(7.3)$ & $524(89.3)$ & $20(3.4)$ \\
\hline 2006 & $19(3.5)$ & $512(94.4)$ & $11(2.0)$ \\
\hline 2005 & $29(5.4)$ & $500(92.7)$ & $10(1.8)$ \\
\hline
\end{tabular}

Number of blood transfusions ranged from 4-18 per year (Table 3 ).

Table 3

Number of blood transfusions per year

\begin{tabular}{|c|c|c|c|}
\hline $\begin{array}{l}\text { No. of transfusions } \\
\text { per year }\end{array}$ & $\mathbf{2 0 0 7}$ & $\mathbf{2 0 0 6}$ & $\mathbf{2 0 0 5}$ \\
\hline $4-6$ & 03 & 02 & 03 \\
\hline $7-9$ & 12 & 13 & 15 \\
\hline $10-12$ & 33 & 27 & 24 \\
\hline $13-15$ & 07 & 12 & 10 \\
\hline $16-18$ & 00 & 01 & 01 \\
\hline
\end{tabular}

Many patients who had $<10$ blood transfusions per year were newly diagnosed but two patients aged 11 and 16 years respectively had 6-8 blood transfusions per year while their average pre-transfusion haemoglobin ranged from $6.6-7.6 \mathrm{mg} / \mathrm{dl}$ throughout the 3 years.
Eleven patients had had splenectomy, all done after the age of five years. A proportion of the patients with an annual transfusion requirement $>220$ $\mathrm{ml} / \mathrm{kg} /$ year had already had splenectomy (Table 4).

Table 4

Patients having blood transfusion requirement $>220 \mathrm{ml} / \mathrm{kg} /$ year

\begin{tabular}{|l|c|c|c|}
\hline & $\mathbf{2 0 0 7}$ & $\mathbf{2 0 0 6}$ & $\mathbf{2 0 0 5}$ \\
\hline $\begin{array}{l}\text { Annual transfusion } \\
\text { requirement } \\
>\mathbf{2 2 0} \text { ml/kg/year }\end{array}$ & 15 & 14 & 15 \\
\hline $\begin{array}{l}\text { Number who had } \\
\text { splenectomy }\end{array}$ & 01 & 02 & 05 \\
\hline
\end{tabular}

Serum ferritin levels are shown in Table 5. Almost $50 \%$ of the patients had serum ferritin levels above the potentially cardiotoxic level of $2500 \mu \mathrm{g} / 1$. A significant proportion had not had serum ferritin levels done for the year.

Table 5

Serum ferritin levels

\begin{tabular}{|c|c|c|c|}
\hline Serum ferritin $\boldsymbol{\mu g} / \mathbf{l}$ & $\mathbf{2 0 0 7}$ & $\mathbf{2 0 0 6}$ & $\mathbf{2 0 0 5}$ \\
\hline$<\mathbf{1 0 0 0}$ & 05 & 07 & 07 \\
\hline $\mathbf{1 0 0 0 - 2 5 0 0}$ & 16 & 19 & 16 \\
\hline$>\mathbf{2 5 0 0}$ & 20 & 25 & 17 \\
\hline Not done & 13 & 3 & 13 \\
\hline Total & $\mathbf{5 4}$ & $\mathbf{5 4}$ & $\mathbf{5 3}$ \\
\hline
\end{tabular}

With regard to iron chelation 42 patients were on subcutaneous desferrioxamine infusions, 5 were on oral deferiprone and 5 others were on both. Among the patients on desferrioxamine, parents were asked how frequently desferrioxamine subcutaneous infusions were actually given. We did not record the actual prescribed frequency. The frequency for the year 2007 according to information provided by parents is given in Table 6 .

Table 6

Frequency of desferrioxamine infusions per month

\begin{tabular}{|c|c|}
\hline $\begin{array}{c}\text { Frequency of infusions } \\
\text { (days) per month }\end{array}$ & Number of patients \\
\hline $10-13$ & 03 \\
\hline $14-17$ & 13 \\
\hline $18-21$ & 25 \\
\hline $22-25$ & 05 \\
\hline $26-28$ & 01 \\
\hline
\end{tabular}

According to the number of vials used per day as stated by parents, average daily dose of subcutaneous desferrioxamine was calculated. More than $50 \%$ of the patients were receiving doses $>40 \mathrm{mg} / \mathrm{kg} /$ day (table 7). 
Table 7

Average daily dose of desferrioxamine (2007)

\begin{tabular}{|c|c|}
\hline Dose- $\mathbf{~ m g / k g / d a y}$ & Number of patients \\
\hline$<20$ & 00 \\
\hline $20-40$ & 19 \\
\hline$>40$ & 28 \\
\hline
\end{tabular}

Patients were grouped according to the dose of desferrioxamine and frequency of dosing (table 8).

Table 8

Dosage frequency according to average daily dose

\begin{tabular}{|c|c|c|c|c|}
\hline $\begin{array}{c}\text { Dose } \\
\mathbf{m g} / \mathbf{k g} / \mathbf{d a y}\end{array}$ & \multicolumn{4}{|c|}{ Frequency of infusions per month } \\
\cline { 2 - 5 } & $\mathbf{1 0 - 1 5}$ & $\mathbf{1 6 - 2 0}$ & $\mathbf{2 1 - 2 5}$ & $\mathbf{2 6 - 2 8}$ \\
\hline $20-40$ & 0 & 15 & 03 & 01 \\
\hline$>40$ & 07 & 19 & 02 & 0 \\
\hline
\end{tabular}

All 7 patients who were receiving doses 15 days per month or less belonged to the higher dose category. The average dose of deferiprone was $35.4 \mathrm{mg} / \mathrm{kg} / \mathrm{day}$ $(n=10)$.

Parents were asked to comment on compliance. Depending on the number of vials used out of total prescribed, compliance index of desferrioxamine ranged from $33.5 \%-100 \%$ with an average of $83.2 \%$ $(\mathrm{n}=46)$. Compliance index for deferiprone was $100 \%$.

The following known complications were noted in our patients (Table 9). Local skin reactions to subcutaneous infusions and generalized urticaria were grouped together as allergic reactions. Some of the audit indicators and observed findings in this audit are listed in table 10.

Table 9

Frequency of some known complications of thalassaemia

\begin{tabular}{|c|l|c|}
\hline \multicolumn{1}{|c|}{ Complication } & No. of patients (N=61) \\
\hline Disease induced & Chronic skin infection & 2 \\
\hline \multirow{4}{*}{$\begin{array}{c}\text { Iron overload } \\
\text { induced }\end{array}$} & Cardiac failure diagnosed by echocardiography & 7 \\
\cline { 2 - 3 } & Delayed puberty in girls (no signs of puberty at 14 years of age) & 5 \\
\cline { 2 - 3 } & Diabetes mellitus & 2 \\
\cline { 2 - 3 } Iron chelation \\
induced & Hypoparathyroidism & 1 \\
\cline { 2 - 3 } & Allergic reactions to subcutaneous desferrioxamine & 3 \\
\cline { 2 - 3 } & Allergic reactions to oral deferiprone & 2 \\
\cline { 2 - 3 } & Allergic reactions to subcutaneous desferrioxamine and oral & \\
\cline { 2 - 3 } & Arthropathy (desferrioxamine) & 2 \\
\cline { 2 - 3 } & Arthropathy (deferiprone) & 2 \\
\cline { 2 - 3 } & Impaired hearing diagnosed by audiometry & 3 \\
\cline { 2 - 3 } & Retinopathy (fundoscopy) & 7 \\
\hline
\end{tabular}

Table 10

Comparison of standards and observed findings in the audit

\begin{tabular}{|l|c|c|c|}
\hline \multicolumn{1}{|c|}{ Indicator } & Standard & Observed in the audit \\
\cline { 2 - 4 } & All patients & Number & Percentage \\
\hline $\begin{array}{l}\text { Maintenance of adequate past medical } \\
\text { records (thalassaemia record books) }\end{array}$ & All patients & $74 \%$ \\
\hline Age appropriate hepatitis B immunisation & All patients in whom splenectomy is & 11 & $100 \%$ \\
\hline $\begin{array}{l}\text { Splenectomy only after 5 years of age (if } \\
\text { indicated) }\end{array}$ & All patients & 00 & $0 \%$ \\
\hline $\begin{array}{l}\text { Pre-transfusion haemoglobin level of 9-10.5 } \\
\text { mg/dl }\end{array}$ & All growing children who are on \\
\hline $\begin{array}{l}\text { Standard dose of desferrioxamine for } \\
\text { children 20-40 mg/kg/day }\end{array}$ & 19 & $40 \%$ \\
\hline $\begin{array}{l}\text { Frequency of desferrioxamine infusions at } \\
\text { least 5 days/week }\end{array}$ & All patients who are on desferrioxamine & 31 & $67 \%$ \\
\hline Compliance index of 100\%-desferrioxamine & All patients & 25 & $54 \%$ \\
\hline Compliance index of 100\%-deferiprone & All patients & 10 & $100 \%$ \\
\hline
\end{tabular}




\section{Discussion}

Data was recorded from 61 confirmed beta thalassaemia major patients. We are confident that data was collected from more than $90 \%$ of beta thalassaemia major patients treated at LRH. Male to female ratio was 1: 0.91 .

Despite being a hospital for children, thalassaemia patients up to the age of 24 years are being treated at this hospital. This probably indicates the need to strengthen measures to build up confidence in the patients before they are transferred to adult care institutions. This may involve improving facilities available in these institutions.

Many patients were treated for 'transfusion dependent anaemia' up to the age of 5 years without having the diagnosis confirmed. Recurrent blood transfusions and inconclusive reports were the reasons. However, early diagnosis is important for initiation of appropriate treatment ${ }^{10,11}$. Diagnostic facilities should be geared to achieve this objective.

Thalassaemia screening is gaining interest in Sri Lanka $^{1,12,13}$. Screening of siblings of thalassaemia patients should be an important first step.

Being a chronic/lifelong illness proper maintenance of medical records is vital. This becomes crucial in the event the patient is transferred to a different institution for further care. It was revealed that some wards maintain an additional copy of patient records in the ward. This was found to be useful as a back up and details of the patient could be reviewed without having to get down the 'patient's record book'.

In order to avoid complications beta thalassaemia major patients should maintain a pre-transfusion haemoglobin level of 9-10.5 $\mathrm{mg} / \mathrm{dl}$ and post transfusion haemoglobin level of $14-15 \mathrm{mg} / \mathrm{dl}^{7}$. The low levels of pre-transfusion haemoglobin reported in this audit may be due to excessive time duration between blood transfusions and/or inadequate volumes of blood transfusion. Post-transfusion haemoglobin should be assessed more frequently to look for the second reason. Despite adequate blood transfusions if the pre-transfusion haemoglobin is low blood transfusions may be needed as frequently as 2 weeks apart ${ }^{7}$. As done in some wards, attendance can be improved by getting the school going children to come for blood transfusions on Saturdays and this is an important step in demonstrating understanding of the child's needs.
Fifteen patients (2007) were having high annual blood transfusions over $220 \mathrm{ml} / \mathrm{kg}$. The reasons need to be investigated. This audit did not record the investigations that were done in these patients.

High percentage of patients getting desferrioxamine above the recommended dose of $20-40 \mathrm{mg} / \mathrm{kg} / \mathrm{day}^{7}$ may be due to some children skipping doses and adding these vials to the next doses. This possibility is further supported by the revelation that all the children who receive less than 15 doses per 4 weeks are in the high dose category.

Compliance to desferrioxamine and deferiprone was similar to previous studies ${ }^{14}$.

This audit recorded prevalence of some of the common side effects of desferrioxamine and deferiprone. However, other side effects like hepatitis, radiographic skeletal changes and growth retardation were not assessed. Side effect profile of deferiprone ${ }^{14,15,16}$ was similar to previous studies but there were only 10 patients on deferiprone. A literature survey did not reveal any previous studies done in Sri Lanka regarding side effect profile of desferrioxamine, hence we compared with a periodical $^{17}$ and the profile of our patients was found to be similar.

\section{Limitations}

Only selected aspects of management were audited. We have based our audit on management guidelines of Thalassaemia International Federation. Some of the patients may have been managed on other accepted guidelines.

\section{Conclusions}

- Despite the provision of facilities free of charge to patients, compliance with the treatment protocol is unsatisfactory.

- As pre-transfusion haemoglobin level is below recommended value in a significant proportion, steps need to be taken to enable patients to come in for blood transfusions at more frequent intervals.

- High proportion of patients had cardiotoxic levels of serum ferritin.

- A specially designed treatment and monitoring programme will be useful in providing optimal care. 


\section{References}

1. de Silva S, Fisher C, Premawardhena A, Lamabadusuriya S, Peto T, Perera G, Old J, Clegg J, Olivieri N, Weatherall D. Thalassaemia in Sri Lanka: implications for the future health burden of Asian populations. The Lancet 2000; 355 (9206): 786-91.

2. Modell M, editor. Guidelines for the control of haemoglobin disorders. WHO Hereditary disease programme, Geneva: 1994.

3. Olivieri NF, Brittenham GM, Mclaren CE, Templeton DM, Cameron RG, McClelland. RA. Et al. Long-term safety and effectiveness of ironchelation therapy with deferiprone for thalassaemia major. New England Journal of Medicine 1998; 339: 417-23.

4. Cohen A, Galanello R, Piga A, Vullo C. A multicenter safety trial of the oral iron chelator deferiprone. Annals of the New York Academy of Sciences 1998; 850: 223-6.

5. Lucas GN, Perera BJC, Fonseka EAN, de Silva DDS, Fernandopulle M. A trial of deferiprone in transfusion-dependent iron overloaded children. Ceylon Med J 2000; 45:71-4.

6. Perera DMD, D Gunasekara D, Wijekoon A, Petrou M. Thalassaemia control in developing countries - the Sri Lankan perspective. Ceylon Med J. 2000; 45:12-16.

7. Cappellini MD, Cohen A, Eleftheriou A, Piga A, Porter J, Taher A. Guidelines for the clinical management of thalassaemia. Thalassaemia International Federation. Nicosia, 2007.

8. Eleftheriou A. Compliance to iron chelation therapy with desferrioxamine. Thalassaemia International Federation; 2005.

9. Modell B, Khan M, Darlison M. Survival in thalassaemia major in the UK: data from the UK thalassaemia register. Lancet. 2000; 355: 2051-2

10. Olivieri NF, Muraca GM, O'Donnell A, Premawardhena A, Fisher C, Weatherall DJ. Studies in haemoglobin E beta-thalassaemia. $\mathrm{Br}$ J Haematol 2008; 141(3):388-97.
11. Premawardhena A, De Silva S, Arambepola M, Olivieri NF, Vichinsky EP, Merson L, Muraco G, Allen A, Fisher C, Peto T, Weatherall DJ. Hemoglobin E-beta-thalassemia: Progress report from the International Study Group. Ann $N Y$ Acad Sci. 2005; 1054:33-9.

12. Perera DMD, Gunasekara D, Wijekoon A, Petrou M. Thalassaemia control in developing countries - the Sri Lankan perspective. Ceylon Medical Journal, 2000; 45:12-16

13. Mudiyanse RM. Thalassemia treatment and prevention in Uva province, Sri Lanka: a public opinion survey. Hemoglobin. 2006; 30(2): 275 89.

14. Olivieri NF, Brittenham, Matsui D, Berkovitch M, Blendis LM, Cameron RG, McClelland RA, Liu PP, Templeton DM, Koren G. Iron chelation therapy with oral deferiprone in patients with thalassaemia major. The New England Journal of Medicine. 1995; 332(14): 918-22.

15. Lucas GN, Perera BJC, Fonseka EAN, de Silva DDS, Fernandopulle M, Karunatilaka DH, Weerasinghe I. Experience with the oral iron chelator deferiprone in transfusion-dependent children. Ceylon Med J 2002; 47:119-21.

16. Taher A, Chamoun FM. Koussa S, Abi Saad M, Khoriaty AI, Neeman R, Mourad FH. Efficacy and side effects of deferiprone (L1) in thalassaemia patients not compliant with desferrioxamine. Acta Haematologica. 1999; 101(4): 173-7.

17. Royal Pharmaceutical Society of Great Britain, RCPCH Publications Ltd. BNF for Children 2005. BMJ Publishing Group Ltd; 2005. p. 469 